\title{
Prevalence of depression and associated factors among HIV/AIDS patients attending antiretroviral therapy clinic at Dessie referral hospital, South Wollo, Ethiopia
}

\author{
Seada Seid ${ }^{1}$, Oumer Abdu², Mebratu Mitiku² and Koku Sisay Tamirat ${ }^{3^{*}}$
}

\begin{abstract}
Introduction: Depression is one of the common mental health disorders and predicted to be the second cause of the global health burden by the year 2020. Depression in HIV patients may lead to poor engagement to their HIV care which may finally result in poor treatment outcomes. Therefore, the aim of this study was to assess the prevalence of depression and associated factors among HIV/AIDS patients on ART at Dessie referral hospital.

Methods: An institution based cross-sectional study was conducted among 395 HIV positive adult patients on antiretroviral treatment from November to January 2019. The study participants were selected by using the systematic random sampling technique among patients who visited the antiretroviral (ART) clinic in the hospital and standardized Patients Health Questionnaire (PHQ-9) was used to measure depression. Descriptive statistics like percentage, median with interquartile range (IQR) was computed and presented in the form of text and table. Binary logistic regression model was fitted to identify factors associated with depression. An adjusted odds ratio (AOR) with a 95\% confidence interval (Cl) was used to identify factors associated with depression.

Result: The prevalence of depression was found to be $20 \%$ with $(95 \% \mathrm{Cl} 16.2,23.8)$. Age group of $25-34$ years $(\mathrm{AOR}=6.58,95 \% \mathrm{Cl} 1.11,38.9)$, widowed marital status $(\mathrm{AOR}=7.05,95 \% \mathrm{Cl} 2.32,21.38)$, perceived stigma $(\mathrm{AOR}=2.43$, $95 \% \mathrm{Cl} 1.13,5.21)]$, had opportunistic infections $[\mathrm{AOR}=4.96,95 \% \mathrm{Cl}(1.05,23.34)]$, HIV non-disclosed HIV status $(\mathrm{AOR}=6.34,95 \% \mathrm{Cl} 1.34-29.65)$, poor and fair drug adherence (AOR $=7.1,95 \% \mathrm{Cl} 2.06,24.44), \mathrm{CD} 4$ count $\leq 200$ $(A O R=5.38,95 \% \mathrm{Cl} 2.37-12.23)$ were factors significantly associated with depression.

Conclusion: The magnitude of depression was relatively lower than the pooled estimates for Ethiopia. Perceived stigma, younger age, widowed, being symptomatic, fair and poor adherence, recent opportunistic infection, low CD4 count, and HIV status not disclosed were positively associated with depression. This finding suggests the integration of mental health care with antiretroviral therapy and the special emphasis ought to be given for those at higher risk of depression.
\end{abstract}

Keywords: Depression, HIV/AIDS, Dessie, Ethiopia

\footnotetext{
*Correspondence: kokusisay23@gmail.com

${ }^{3}$ Department of Epidemiology and Biostatistics, Institute of Public Health,

College of Medicine and Health Science, University of Gondar, Gondar, Ethiopia

Full list of author information is available at the end of the article
}

\section{Background}

Mental health problems accounted for $13 \%$ of the global burden of disease and are highly intertwined with infectious diseases like HIV/AIDS [1,2]. Depression is mental health disorder which is characterized by depressed mood, loss of interest or pleasure, decreased

c) The Author(s) 2020. This article is licensed under a Creative Commons Attribution 4.0 International License, which permits use, sharing, adaptation, distribution and reproduction in any medium or format, as long as you give appropriate credit to the original author(s) and the source, provide a link to the Creative Commons licence, and indicate if changes were made. The images or other third party material in this article are included in the article's Creative Commons licence, unless indicated otherwise in a credit line to the material. If material is not included in the article's Creative Commons licence and your intended use is not permitted by statutory regulation or exceeds the permitted use, you will need to obtain permission directly from the copyright holder. To view a copy of this licence, visit http://creativeco mmons.org/licenses/by/4.0/. The Creative Commons Public Domain Dedication waiver (http://creativecommons.org/publicdomain/ zero/1.0/) applies to the data made available in this article, unless otherwise stated in a credit line to the data. 
energy, feelings of guilt or low self-worth, disturbed sleep or appetite and poor concentration [3, 4]. Currently, an estimated 350 million peoples are affected by depression worldwide and predicted to be the second most important cause of the global disease burden by the year 2020 [3, 4]. However, in low- and middleincome countries treatment and support services for depression are often absent or underdeveloped. An estimated $76-85 \%$ of people suffering from mental disorders in these countries lack access to the treatment they need.

According to the global HIV/AIDS 2017 report, 36.7 million people were estimated to live with HIV/ AIDS. About two-thirds of the HIV infected people in the world were located in sub-Saharan Africa and around $43 \%$ of new cases were in Eastern and Southern Africa including Ethiopia [5]. Ethiopia is one of the sub-Saharan countries highly affected by HIV, though the prevalence decreased from $1.5 \%$ in 2011 to $1.16 \%$ in 2017, it is still a great public health problem [6, 7]. Due stigmatizing nature of the disease depressive disorder was three times higher among HIV infected individuals, the lifetime prevalence of depression range from 22 to $45 \%$ [8, 9] compared to those HIV negative which is 3 to $17 \%$ [10]. Depression associated with different unfavorable health outcomes among HIVAIDS patients like, increased suicidal attempt, hopelessness, poor drug adherence, fast disease progression, drug resistance, treatment failure and decreased quality of life of patients. This may lead to hospitalization and the increasing cost of medical care.

Depression among HIV patients is related to a combination of clinical and socio-demographic factors. Some of clinical factors might be relatively unique to HIV patient, such as AIDS-related stigma [11], compromised immune status (low CD4 counts) and opportunistic infections [12]; on the other hand socio-demographic factors including gender, low educational level and unemployment have been associated with depression in both HIV negative and positive populations [13].

However, most health professionals fail to recognize depression and other mental problems among HIV/AIDS patients due to lack of regular screening and integrated services. There are limited studies that assessed the magnitude and predictors of depression among HIV patients. Moreover, the available didn't address important clinical characteristics that might be associated with depression.

Therefore, this study aimed to assess the prevalence and associated factors of depression among HIV/AIDS patients. Findings from this study could help clinicians for appropriate patient management. In addition, it could be also useful as entry point for the integration of mental health care services with antiretroviral treatment.

\section{Methods}

\section{Study design, setting and period}

An institution-based cross-sectional study was conducted from November to January, 2019, at Dessie referral hospital. The hospital is found in the Amhara region located $401 \mathrm{~km}$ far from Addis Ababa, the capital city of Ethiopia. The hospital is serving more than five million people of the town and nearby districts. In addition to the general services, the hospital also provides antiretroviral therapy services for more than 6 , 763 HIV/AIDS (6279 adults and 484 pediatric) patients since the service started.

\section{Population and samples}

Patients aged 18 years and above and took ART treatment for at least 6 months and attending ART clinic during the data collection period were the study population.

The sample size was determined by using single proportion formula with the assumptions of prevalence (P) of depression among HIVAIDS positive adults (38.94\%) obtained from a study conducted in Debrebrhan [14] hospital, 95\% confidence level, margin of error 5\%, and $10 \%$ non-response rate and the final sample size became 403. Finally, the study participants selected by using systematic random sampling technique among ART clinic visitors.

\section{Data collection procedure}

Before initiation of the data collection process questionnaire was prepared in English by reviewing different literatures then translated to local language Amharic to keep its consistencies. The data collection tool has socio demographic, clinical, stigma, psychosocial and depression measurement questions. Depression was measured using the nine-item standardized Patient Health Questionnaire (PHQ-9) depressive symptoms scale. It has a Likert scale with the following response options: $0=$ not at all, $1=$ several days, $2=$ more than half the days, and $3=$ nearly every day. It has $0-27$ scoring as minimal (1-4), mild (5-9), moderate (10-14), moderately severe (15-19) and severe depressive symptoms (20-27). This is one of the most widely used scales and has been also used in Ethiopia, it is reliable, valid, sensitive and specific to measure depression [15].

Data were collected by interview administered questionnaire to recall for depressive symptoms within 2 weeks, other socio-demographic and clinical characteristics harvested through patient document review. To ensure the validity of the study pretest of the tool and 2 days training was given for two data collectors and one 
supervisor about the objective of the study and how to make and interview with HIV/AIDS patients.

Depression: Participants who were interviewed and scored five and above using patient health questioner 9 (PHQ-9) were considered as depressed [15].

Good adherence: If the average adherence level (95\% or more adherence $=$ missing $\leq 2$ doses of 30 doses or $\leq 3$ doses of 60 doses) and try to assess by asking the missed doses with in the past 3 days, within 1 week and within 1 month [16].

Fair adherence : $(85-94 \%$ or $4-8$ doses missed per month) [16].

Poor adherence: (less than $85 \%$ or $\geq 9$ doses missed per month) [16].

Perceived stigma: Participants who scored above the median score $\geq 24$ were perceived stigma and who scored below the median score $(<24)$ were not perceived stigma measured by using the HIV stigma scale [17].

Social support: The OSS-3 scores ranged from 3 to 14 with a score of $3-8=$ poor support; $9-11=$ moderate support; and $12-14=$ strong support [18].

Body Mass Index: based on Nutritional assessment classification underweight $<18.5 \mathrm{~kg} / \mathrm{m} 2$, Normal $=18.5$ $24.9 \mathrm{~kg} / \mathrm{m} 2$, over weight $\geq 25 \mathrm{~kg} / \mathrm{m} 2$ [19].

\section{Data processing and analysis}

The data was cleaned and entered into Epi info version 7 then exported to STATA Version 14 for data management and analysis. Descriptive statistics like percentage, median (IQR) were used to summarize socio-demographic and clinical characteristics and presented in the form of text, table and graphs. Binary logistic regression model was fitted to identify factors associated with depression on HIV/AIDS patients. Crude and adjusted odds ratio with $95 \%$ CI computed to see the presence and strength of association between independent variables and depression. Variables having a p-value of 0.05 and less in the multivariable logistic model considered as significantly associated with depression. Model fitness was checked by using Hosmer and Lemeshow goodness of fit test.

\section{Ethical consideration}

Ethical clearance was obtained from the University of Gondar College of medicine and health sciences ethical review committee before data collection process. An official permission letter was also written to Dessie referral hospital. Respondents were informed about the purpose of the study and verbal consent was obtained from each respondent. Moreover, all the study participants were informed that they have a full right to decline from the study and they were also assured for an attainment of confidentiality for the information obtained from them.
Patients who had depression during data collection were linked to psychiatry clinic for further treatment and intervention.

\section{Results \\ Socio demographic characteristics}

In this study, a total of 395 HIV/AIDS patients were included with the response rate of $93.5 \%$. The median age of the respondents was 38 [interquartile range (IQR): 10] years and about $46.9 \%$ aged between 35 and 44 years. Two hundred forty-two (61.3\%) of participants were females, $43.3 \%$ were married and about $52.9 \%$ had no formal education. Most of the respondents 357 (90.4\%) were urban dwellers and similarly $80.3 \%$ were living with their families (Table 1).

\section{Clinical characteristics of the respondents}

The majority $(88.4 \%)$ of the respondents were on first line ART regimen, of which TDF-3TC-EFV (34.7\%) and AZT-3TC-NVP (22\%) regimens were commonly used combinations. The majority $(83.5 \%)$ of the respondents were at recent WHO clinical stage I, of whom most (81.3\%) of them had CD4 count of $>200$ cells $/ \mathrm{mm}^{3}$ and about (92.2\%) patients had been on ART for more than 12 months. Regarding to ART adherence, the majority (92.4\%) of the participants had a good drug adherence, 91.9\% had disclosed their HIV status and $45.3 \%$ have faced stigma (Table 2).

\section{Prevalence of depression}

The prevalence of depression was found to be $20 \%$ with (95\% CI 16.2, 23.8). Regarding to the severity of depression, $51.9 \%, 39.2 \%, 7.6 \%$ and $1.3 \%$ had mild, moderate, moderately sever and severe depression, respectively. The prevalence of depression among male and female patients was found to be $18.3 \%$ and $21.07 \%$, respectively.

\section{Factors associated with depression}

In the multivariable logistic regression analysis, age group of 25-34 year, widowed marital status, perceived stigma, CD4 count $\leq 200$ cells $/ \mathrm{mm}^{3}$, symptomatic patients (WHO stage II and above), non-disclosed HIV status, recent opportunistic infections and fair and poor drug adherence were significantly associated with depression.

As a result, those participants who were widowed and age group of 25-34 year, the odds of depression was 7.05 $(\mathrm{AOR}=7.05,95 \% \mathrm{CI} 2.32,21.38)$ and $6.58(\mathrm{AOR}=6.58$, $95 \%$ CI 1.11, 38.95) times higher compared single ones and those of older than 55 year, respectively. Similarly, symptomatic patients and those with CD4 count $\leq 200$, the odds of depression was 2.51 [AOR $=2.51,95 \% \mathrm{CI}$ $(1.38,4.56)]$ and 5.94 [AOR $=5.94,95 \% \mathrm{CI}(2.68,13.62)]$ times higher compared to those who were clinically 
Table 1 Socio demographic characteristics of HIV positive patients in Dessie referral hospital, South Wollo, Ethiopia $(\mathrm{n}=395)$

\begin{tabular}{|c|c|c|c|}
\hline Characteristics & Category & Frequency(n) & Percentage (\%) \\
\hline \multirow[t]{5}{*}{ Age } & $18-24$ & 13 & 3.3 \\
\hline & $25-34$ & 114 & 28.8 \\
\hline & $35-44$ & 182 & 46.1 \\
\hline & $45-54$ & 58 & 14.6 \\
\hline & $\geq 55$ & 28 & 7 \\
\hline \multirow[t]{2}{*}{ Sex } & Male & 153 & 38.7 \\
\hline & Female & 242 & 61.3 \\
\hline \multirow[t]{2}{*}{ Residence } & Urban & 357 & 90.4 \\
\hline & Rural & 38 & 9.6 \\
\hline \multirow[t]{4}{*}{ Marital status } & Married & 176 & 44.5 \\
\hline & Single & 74 & 18.7 \\
\hline & Divorced & 60 & 15.3 \\
\hline & Widowed & 85 & 21.5 \\
\hline \multirow[t]{4}{*}{ Level of education } & No formal education & 209 & 52.9 \\
\hline & Primary school & 93 & 23.5 \\
\hline & Secondary school & 60 & 15.2 \\
\hline & Diploma and above & 33 & 8.3 \\
\hline \multirow[t]{6}{*}{ Occupation } & Unemployed & 18 & 4.5 \\
\hline & Government employed & 69 & 17.5 \\
\hline & Housewife & 144 & 36.5 \\
\hline & Daily laborer & 99 & 25.1 \\
\hline & Merchant & 37 & 9.3 \\
\hline & Farmers & 28 & 7.1 \\
\hline \multirow[t]{2}{*}{ Income in ETB } & $<2000$ & 234 & 59.2 \\
\hline & $\geq 2000$ & 161 & 40.8 \\
\hline \multirow[t]{2}{*}{ With whom you live } & Rented accommodation & 186 & 47.1 \\
\hline & Own home & 209 & 52.9 \\
\hline
\end{tabular}

stable and had higher CD4 count, respectively. Likewise, patients who experienced stigma and didn't disclosed their HIV status, the odds of depression was 2.28 $[\mathrm{AOR}=2.28,95 \% \mathrm{CI}(1.12,4.94)]$ and $5.38[\mathrm{AOR}=5.38$, 95\% CI $(1.083,26.73)]$ times higher compared to their counter parts. Recent opportunistic infections also associated with 5.18 times higher odds of depression compared to those who had no such history $[\mathrm{AOR}=5.18$, 95\% CI $(1.12,24.55)]$. Furthermore, those who had fair and poor drug adherence, the odds of depression was six times higher compared to those good adherence $[\mathrm{AOR}=5.96,95 \% \mathrm{CI}(1.74,20.52)]$ (Table 3$)$.

\section{Discussion}

This study showed that the prevalence of depression was $20 \%$ with $95 \%$ CI $(16.2,23.8)$. This finding is higher than studies done in Ethiopia in different places Debremarkos (11.7\%) [11] and Axum (14.6\%) [20]. On the other hand this finding is lower than studies done in other parts of Ethiopia, which ranged from $38.4 \%$ to $76.7 \%$ [14, 21-29].
The prevalence of depression in this study is similarly lower when compared to a systematic review and metaanalysis of east Africa studies (38\%) [30], and another pooled estimates in Ethiopia (36.65\%) [31] and a systemic review in China 60\% [32]. This discrepancy might be due to the variation in sample size, the population being studied, the study period, inclusion criteria and measurement tools used to assess depression. For instance in the study done in Bahirdar depression was measured using the hospital anxiety and depression scale (HADS), whereas a study conducted in Tigray depression was measured by using the 21 items Hamilton's depression scale Questionnaire. In addition, most of our study participants were clinically stable and most took ART for at least 6 months where immunological recovery achieved.

This study showed that the odds of depression was higher among younger age group patients compared to elders. This could be due to the fact that HIV/AIDS is stigmatizing disease that affects psychosocial wellbeing of patients. Similarly, this study also revealed that 
Table 2 Clinical and behavioral characteristics of study participants at Dessie referral hospital, South Wollo, Ethiopia, 2019 ( $n=395)$

\begin{tabular}{|c|c|c|c|}
\hline Characteristics & Category & Frequency (n) & Percentage (\%) \\
\hline \multirow[t]{2}{*}{ ART regimen } & First line & 349 & 88.4 \\
\hline & Second line & 46 & 11.6 \\
\hline \multirow[t]{2}{*}{ Duration since known to have HIV } & $\leq 12$ & 24 & 6.1 \\
\hline & $>12$ & 371 & 93.9 \\
\hline \multirow[t]{2}{*}{ Recent CD4 count } & $\leq 200$ & 74 & 18.7 \\
\hline & $>200$ & 321 & 81.3 \\
\hline \multirow[t]{3}{*}{ Recent viral load } & Not detected & 279 & 70.6 \\
\hline & Up to 999 & 31 & 7.9 \\
\hline & $>1000$ & 85 & 21.5 \\
\hline \multirow[t]{2}{*}{ Hgb level } & $<12$ & 55 & 13.9 \\
\hline & $\geq 12$ & 340 & 86.1 \\
\hline \multirow[t]{4}{*}{ WHOT stage } & Stage 1 & 330 & 83.5 \\
\hline & Stage II and above & 37 & 9.4 \\
\hline & Stage III & 23 & 5.8 \\
\hline & Stage IV & 5 & 1.3 \\
\hline \multirow[t]{2}{*}{ Recent adherence to HHART } & Good & 365 & 92.4 \\
\hline & Fair and poor & 30 & 7.6 \\
\hline \multirow[t]{2}{*}{ Opportunistic infections } & Yes & 31 & 7.8 \\
\hline & No & 364 & 92.2 \\
\hline \multirow[t]{2}{*}{ Recent hospitalization } & Yes & 21 & 5.3 \\
\hline & No & 364 & 94.7 \\
\hline \multirow[t]{2}{*}{ Stigma } & Yes & 179 & 45.3 \\
\hline & No & 216 & 54.7 \\
\hline \multirow[t]{2}{*}{ Disclosed HIV status } & Yes & 374 & 94.7 \\
\hline & No & 21 & 5.3 \\
\hline \multirow[t]{2}{*}{ Cigarette smoking } & Yes & 6 & 1.5 \\
\hline & No & 389 & 98.5 \\
\hline \multirow[t]{2}{*}{ Khat chewing } & Yes & 38 & 9.6 \\
\hline & No & 357 & 90.4 \\
\hline \multirow[t]{2}{*}{ Alcohol intake } & Yes & 17 & 4.3 \\
\hline & No & 378 & 95.7 \\
\hline \multirow[t]{2}{*}{ Suicidal ideation } & Yes & 32 & 8.1 \\
\hline & No & 363 & 91.9 \\
\hline \multirow[t]{2}{*}{ Suicidal attempt } & Yes & 6 & 1.5 \\
\hline & No & 389 & 98.5 \\
\hline \multirow[t]{3}{*}{ Social support } & Poor & 223 & 56.4 \\
\hline & Moderate & 158 & 40 \\
\hline & Strong & 14 & 3.5 \\
\hline
\end{tabular}

widowed marital status was associated with increased occurrence of depression compared to those married. This finding was supported by previous studies in Ethiopia (16). Death of marital partner and loved one associated with pathological grief and bereavement leads to sadness and loneliness that could increase depression [33].
Perceived stigma associated with increased occurrence of depression compared to those who didn't experience stigma. This result is consistent with those of previous studies done in Ethiopia [22, 24-26, 29] and Uganda [13]. Perceived stigma go along with low self-image, social isolation and ultimately steered to develop psychological distress and depression [34]. 
Table 3 Factors associated with depression among HIV/ AIDS patients on ART at Dessie referral hospital, South Wollo, Ethiopia, $2019(n=395)$

\begin{tabular}{|c|c|c|c|c|}
\hline \multirow[t]{2}{*}{ Category } & \multicolumn{2}{|c|}{ Depression } & \multirow[t]{2}{*}{ COR $(95 \% \mathrm{Cl})$} & \multirow[t]{2}{*}{ AOR $(95 \% \mathrm{Cl})$} \\
\hline & Yes & No & & \\
\hline \multicolumn{5}{|l|}{ Age } \\
\hline $18-24$ & 5 & 8 & $2.29(.412,13.98)$ & $1.53(0.1,22.66)$ \\
\hline $25-34$ & 37 & 77 & $1.76(1.12,13.96)$ & $6.58(1.11,38.95)$ * \\
\hline $35-44$ & 25 & 157 & $0.58(0.43,5.44)$ & $1.35(.251,7.27)$ \\
\hline $45-54$ & 6 & 52 & $0.42(0.22,4.08)$ & $1.01(.144,7.17)$ \\
\hline$\geq 55$ & 6 & 22 & 1 & 1 \\
\hline \multicolumn{5}{|l|}{ Marital status } \\
\hline Married & 9 & 167 & 1 & 1 \\
\hline Single & 20 & 54 & $6.87(2.95,15.99)$ & $3.33(0.98,18.9 .4)$ \\
\hline Divorced & 8 & 52 & $2.86(1.05,7.78)$ & $0.766(0.22,2.66)$ \\
\hline Widowed & 42 & 43 & $18.12(8.19-40.10)$ & $7.05(2.32,21.38) *$ \\
\hline \multicolumn{5}{|c|}{ Perceived stigma } \\
\hline Yes & 50 & 129 & $2.45(1.502,4.16)$ & $2.43(1.13,5.21) *$ \\
\hline No & 29 & 187 & 1 & 1 \\
\hline \multicolumn{5}{|c|}{ Suicidal ideation } \\
\hline Yes & 23 & 13 & $9.57(4.58,20.01)$ & $4.33(0.98,16.28)$ \\
\hline No & 56 & 303 & 1 & 1 \\
\hline \multicolumn{5}{|l|}{ Adherence } \\
\hline Fair and poor & 22 & 8 & $14.86(6.31,35.01)$ & $7.1(2.14,24.44) *$ \\
\hline Good & 57 & 308 & 1 & 1 \\
\hline \multicolumn{5}{|c|}{ Opportunistic infection } \\
\hline Yes & 18 & 13 & $6.88(3.20,14.77)$ & $4.96(1.05,23.34) *$ \\
\hline No & 61 & 303 & 1 & 1 \\
\hline \multicolumn{5}{|c|}{ Recent hospitalization } \\
\hline Yes & 15 & 6 & $12.11(4.52,32.4)$ & $1.63(0.27,9.55)$ \\
\hline No & 64 & 310 & 1 & 1 \\
\hline \multicolumn{5}{|l|}{ Disclosure } \\
\hline No & 15 & 6 & $12.11(4.52,32.4)$ & $6.34(1.36,29.65) *$ \\
\hline Yes & 64 & 310 & 1 & 1 \\
\hline \multicolumn{5}{|l|}{ Social support } \\
\hline Poor & 56 & 167 & $2.01(.44,9.27)$ & $0.67(0.07,6.43)$ \\
\hline Moderate & 21 & 137 & $0.92(0.19,4.4)$ & $0.34(0.03,3.33)$ \\
\hline Strong & 2 & 12 & 1 & 1 \\
\hline \multicolumn{5}{|l|}{ WHOT stage } \\
\hline Stage I & 55 & 275 & 1 & 1 \\
\hline $\begin{array}{l}\text { Stage II and } \\
\text { above }\end{array}$ & 24 & 41 & $2.93(1.64,5.24)$ & $0.84(.26,2.63) *$ \\
\hline \multicolumn{5}{|c|}{ Recent CD4 count } \\
\hline$\leq 200$ & 37 & 37 & $6.64(3.79,11.62)$ & $5.38(2.37,12.23) *$ \\
\hline$>200$ & 42 & 279 & 1 & 1 \\
\hline
\end{tabular}

* Show a p-value less than 0.05

Immunocompromised condition reflected by low CD4 count and those who are symptomatic were associated depression occurrence compared to those clinically stable and had high CD4 count. This result is consistent with studies done in Hawassa, Ethiopia [26] and Malawi [35]. Similarly, a study conducted in Uganda showed that CD4 count $>200$ was associated with lower occurrence of depression (protective) [13]. Similarly a study conducted in Ethiopia Yekatit 12 hospital [28] showed that CD4 count $<250$ was associated with depression and similar finding in Cameron showed that CD4 count $<100$ was associated with high depression [6]. Besides systematic review done in Greece showed that symptomatic patients were more depressed than non-symptomatic patients [36].

In addition, this study also showed that recent opportunistic infections were associated with increased occurrence of depression. Opportunistic infections often associated with hospitalization and diminished functional status which could affect patient's psychosocial and economic conditions. This result is in agreement with a study done in Alert hospital, Ethiopia [25].

Moreover, patient who were not strictly adherent to their antiretroviral medication were more depressed than those in good adherence. Poor adherence may cause instable clinical condition and loosen patient-physician relationship, ultimately leads to diminished concentration, and feelings of worthlessness and disrupt selfmanagement activities. However, due the cross-sectional nature of the study poor adherence might be the result of depression which is the limitation of the study and difficult to establish cause-effect relationship. This finding is in agreement with a study done in Ethiopia [25, 12, 20, 28, 29] and Korea [37].

Furthermore, non-disclosed HIV status was associated with increased depression occurrence compared to those who disclosed their HIV status. This result is consistent with a study done in Dilla, Ethiopia [38].

This study had strengths of assessing the burden of mental health problems among HIV/AIDS which could be helpful for program consideration and service integration. However, institutional and cross-sectional nature of the study may limit the cause and effect and affect representativeness of the findings. In addition, there may be recall bias from respondents.

\section{Conclusion}

The magnitude of depression was relatively lower than pooled estimates of Ethiopia. Perceived stigma, widowed marital status, being symptomatic, fair and poor adherence, recent opportunistic infection, low CD4 count and non-disclosed HIV status were associated with depression. This finding suggests that depression is a huge problem on HIV patients. Thus integrating mental health care with antiretroviral therapy might be helpful. Special emphasis ought to be given for those at higher risk of depression. 


\begin{abstract}
Abbreviations
AIDS: Acquired Immunodeficiency Syndrome; AOR: Adjusted odds ratio; ART : Antiretroviral therapy; ARVs: Anti Retro Virus; BMI: Body Mass Index; CD4: Cluster of cell Differentiation 4; Cl: Confidence interval; COR: Crude Odds Ratio; FMOH: Federal Ministry of Health; HAAR: Highly Active Anti Retro Viral Therapy; HIV: Human immunodeficiency virus; IQR: Inter quartile range; NACP: National Acquired immunodeficiency Syndrome Control Program; Ol: Opportunistic infections; PHQ-9: Patients Health Questionnaire; PLWHA: People living with HIV; UNAIDS: United Nations Program on Acquired Immune Deficiency Syndrome; WHO: World Health Organization.
\end{abstract}

\section{Acknowledgements}

We would like to thank data collectors, supervisors and study participants for their collaboration and contribution of the study. Finally, we would like to thank all who directly or indirectly supported us.

\section{Authors' contributions}

SS, OA, MM, and KST conceived the study, involved in the study design, data collection and analysis, drafted the manuscript and critically reviewed the manuscript. All authors read and approved the final manuscript.

\section{Funding}

We received funding from Amhara regional health bureau.

\section{Availability of data and materials}

The datasets used during the current study is available from the corresponding author on reasonable request.

\section{Ethics approval and consent to participate}

Ethical clearance was obtained from University of Gondar College of medicine and Health Science School of medicine ethical review committee before data collection process. An official letter was written to Dessie referral Hospital. Respondents were informed about the objective and purpose of the study and verbal consent was obtained from each respondent. Moreover, all the study participants were informed that they have a full right to participate or decline from the study and they were assured for an attainment of confidentiality for the information obtained from them. They were interviewed in separate room and identification was not documented. HIV/AIDS patients who had depression during data collection were linked to psychiatry clinic.

\section{Consent for publication}

Not applicable as there is no image or other confidentiality related issues.

\section{Competing interests}

The authors declare that they have no competing interests.

\section{Author details \\ ${ }^{1}$ Amhara Regional Health Bureau, Borumeda Hospital, Dessie, Ethiopia. \\ ${ }^{2}$ Department of Internal Medicine, College of Medicine and Health Science, University of Gondar, Gondar, Ethiopia. ${ }^{3}$ Department of Epidemiology and Biostatistics, Institute of Public Health, College of Medicine and Health Science, University of Gondar, Gondar, Ethiopia.}

Received: 31 July 2019 Accepted: 23 July 2020

Published online: 29 July 2020

\section{References}

1. FMOH. National Mental Health Strategy 2012/13-2015/16. 2012.

2. WHO. Global burden of mental disorders and the need for a comprehensive, coordinated response from health and social sectors at the country level. 2012.

3. ORGANIZATION, WH., Depression. A Global Public Health Concern Developed by Marina Marcus, M. Taghi Yasamy, Mark van Ommeren, and Dan Chisholm, Shekhar Saxena. WHO Department of Mental Health and Substance Abuse, 2012.

4. WHO. Mental disorders. 9 April 2018.
5. The Global HIV/AIDS Epidemic. 2017.

6. Gaynes BN, et al. Changes in HIV outcomes following depression care in a resource-limited setting: results from a pilot study in Bamenda, Cameroon. PLoS ONE. 2015;10(10):e0140001.

7. HIV related estimates and projections for Ethiopia-2017. 2017.

8. DeJean $\mathrm{D}$, et al. Patient experiences of depression and anxiety with chronic disease: a systematic review and qualitative meta-synthesis. Ontario Health Technol Assess Series. 2013;13(16):1.

9. Weissman MM, et al. Cross-national epidemiology of major depression and bipolar disorder. JAMA. 1996;276(4):293-9.

10. Sadock BJ, Sadock VA. Kaplan \& sadock's comprehensive textbook of psychiatry eighth edition. 2005. II.

11. Kibret GD, Salilih SZ. Prevalence and associated factors of depression among HIV Infected Patients in Debre Markos Town Northwest Ethiopia. International Journal of Emergency Mental Health and Human Resilience, Vol. 17(ISSN 1522-4821). 2015.

12. Mohammed $\mathrm{M}$, et al. Prevalence of depression and associated factors among HIV patients seeking treatments in ART clinics at Harar Town, Eastern Ethiopia. J AIDS Clin Res. 2015;6(474):2.

13. Akena $D$, et al. The association between aids related stigma and major depressive disorder among HIV-positive individuals in Uganda. PLOS ONE. 2012;7(11):e48671.

14. Eshetu1 DA, et al. Prevalence of depression and associated factors among HIV/AIDS patients attending ART clinic at Debrebirhan Referral Hospital,North Showa, Amhara Region,Ethiopia. 2015. 1(1:3).

15. Gelaye B, et al. Validity of the patient health questionnaire-9 for depression screening and diagnosis in East Africa. Psychiatry Res. 2013;210(2):653-61.

16. Ethiopia FMOH. National Guidelines for comprehensive HIV prevention, care and treatment. 2017.

17. Reinius $\mathrm{M}$, et al. Development of a 12-item short version of the HIV stigma scale. Health Quality Life Outcomes. 2017;15(1):115.

18. Abiola T, Udofia O, Zakari M. Psychometric properties of the 3-item oslo social support scale among clinical students of Bayero University Kano, Nigeria. Malaysian J Psychiatry. 2013;22(2):32-41.

19. Consulation W. Waist circumference and body mass index report of $A$ WHO Expert Consultation Geneva; World Health Orgnization. 2011.

20. Gebrezgiabher BB et al. Depression among adult HIV/AIDS patients attending ART Clinics at Aksum Town, Aksum, Ethiopia. 2019.

21. Tareke M, Addisu F, Abate A. Depression among patients attending antiretroviral treatment program in public health facilities in Bahir Dar City, Ethiopia. J Affective Disorders. 2018;232:370-4.

22. Berhe H, Bayray A. Prevalence of depression and associated factors among people living with HIV/AIDS in tigray, North Ethiopia: a cross sectional hospital based study. Int J Pharm Sci Res. 2013;4(2):765.

23. Mohammed M, et al. Prevalence of depression and associated factors among HIV patients seeking treatments in ART clinics at Harar Town, Eastern Ethiopia. J AIDS Clin Res. 2015;6(6):474.

24. Beyene GA, et al. Prevalence and associated factors of depression among HIV patients taking antiretroviral therapy at Zewditu Memorial Hospital, Addis Ababa, Ethiopia. 2014; 3(4).

25. Tesfaw $G$, et al. Prevalence and correlates of depression and anxiety among patients with HIV on-follow up at Alert Hospital, Addis Ababa, Ethiopia. BMC Psychiatry. 2016;16(1):368.

26. Duko B, et al. Prevalence and associated factors of depression among patients with HIV/AIDS in Hawassa, Ethiopia, cross-sectional study. Ann Gen Psychiatry. 2018;17(1):45.

27. Yeneabat T, Bedaso A, Amare T. Factors associated with depressive symptoms in people living with HIV attending antiretroviral clinic at Fitche Zonal Hospital, Central Ethiopia: cross-sectional study conducted in 2012. 2017.

28. Bethelehem chirotaw wondatir and s. Abdelmenan, prevalence and associated factors of depression among hiv positive clients at yekatit 12 Hospital Medical College, Addis Ababa, Ethiopia. 2018.

29. Agazhu HW, BWGA, Wurjine TH. Prevalence and associated factors of depression among HIV/AIDS patients attending antiretroviral therapy clinics at Gurage Zone Selected Government Hospitals, Southwest, South nations, Nationalities and Peoples' Region, Ethiopia, 2018. 2018.

30. Ayano G, Solomon M, Abraha M. A systematic review and meta-analysis of epidemiology of depression in people living with HIV in east Africa. BMC Psychiatry. 2018;18(1):254. 
31. Amare T, et al. Prevalence and associated factors of depression among PLHIV in Ethiopia: systematic review and meta-analysis, 2017. AIDS research and treatment, 2018. 2018.

32. Niu L, et al. The mental health of people living with HIV in China, 1998-2014: a systematic review. PLoS ONE. 2016;11(4):e0153489.

33. World Health Organization. World Organization of Family Doctors (Wonca). Integrating mental health into primary care: a global perspective. Geneva, Switzerland:WHO. 2008.

34. Perlick DA, et al. Stigma as a barrier to recovery: adverse effects of perceived stigma on social adaptation of persons diagnosed with bipolar affective disorder. Psychiatr Serv. 2001;52(16):27-32.

35. Kim MH, et al. Factors associated with depression among adolescents living with HIV in Malawi. BMC Psychiatry. 2015;15(1):264.

36. Arseniou S, Arvaniti A, Samakouri M. HIV infection and depression. Psychiatry Clin Neurosci. 2014;68(2):96-109.
37. Song JY, et al. Depression among HIV-infected patients in Korea: assessment of clinical significance and risk factors. Infect Chemotherapy. 2013;45(2):211-6.

38. Tesfaye SH, Bune GT. Generalized psychological distress among HIV-infected patients enrolled in antiretroviral treatment in Dilla University Hospital, Gedeo zone, Ethiopia. Global health action. 2013;7:23882-23882

\section{Publisher's Note}

Springer Nature remains neutral with regard to jurisdictional claims in published maps and institutional affiliations.
Ready to submit your research? Choose BMC and benefit from:

- fast, convenient online submission

- thorough peer review by experienced researchers in your field

- rapid publication on acceptance

- support for research data, including large and complex data types

- gold Open Access which fosters wider collaboration and increased citations

- maximum visibility for your research: over $100 \mathrm{M}$ website views per year

At BMC, research is always in progress.

Learn more biomedcentral.com/submissions 